\title{
Oral Hygiene Behavior of School Children in Saudi Arabia: A Descriptive Cross-sectional Survey
}

\author{
Subramania PK Kannan ${ }^{1}$, Suliman F Alfahaid ${ }^{2}$, Abdulaziz S Alharbi ${ }^{3}$, Bader S Almutairi ${ }^{4}$, Abdulrahman H Alanazi ${ }^{5}$, \\ Fahad A Alsaab ${ }^{6}$, Saud S Alatallah ${ }^{7}$, Sami D Aldhuwayhi ${ }^{8}$
}

\begin{abstract}
Aim: Oral health is an integral part of general health, and good knowledge and oral hygiene practices are the key to achieving oral health. This study assessed the knowledge, attitude, and oral hygiene practices of school children in Saudi Arabia and the need for dental health education and intervention.

Materials and methods: This descriptive cross-sectional study was conducted among male school children $(n=451)$, aged 6-12 years, in the Al-Zulfi region of Saudi Arabia. Participants were included in this study using one-stage cluster sampling. The subjects completed a questionnaire, and the oral hygiene index-simplified was recorded. The collected data were statistically analyzed using SPSS version 21.

Results: Only $41.9 \%$ of the children had good oral hygiene. Of the sampled children, $72.7 \%$ used a toothbrush and toothpaste, but only $2.2 \%$ were aware of dental floss; $62.7 \%$ children brushed for $1-2$ minutes and had good oral hygiene, but $55.9 \%$ of children had no knowledge about periodontal health. Only $30.1 \%$ parents observed their children during tooth brushing.

Conclusion: Use of a toothbrush and toothpaste is the most commonly used and most effective oral hygiene aid. Brushing twice a day for 1-2 minutes seems to be effective. Oral health care education should be included in the school curriculum, and a parental awareness program is needed to emphasize their role in the dental health of their children.
\end{abstract}

Keywords: Attitude, Dental caries, Dentistry for children, Knowledge, Oral hygiene practice.

International Journal of Clinical Pediatric Dentistry (2020): 10.5005/jp-journals-10005-1710

\section{INTRODUCTION}

Good oral hygiene is considered the way to achieve a healthy mouth, but oral health cannot be achieved if the basic principles of dental hygiene are not incorporated into day-to-day life. Moreover, poor oral health has been proven to have adverse effects on general health. Good oral hygiene practices are best inculcated from childhood, and educating children in proper oral hygiene methods is the collective responsibility of parents, teachers, and dental professionals. ${ }^{1}$

Prevention is considered to be the foundation of modern dental practice; effective control of dental plaque is the main feature of preventive dentistry of oral diseases. The main goal of dental hygiene is to prevent the formation of plaque. Poor oral hygiene allows the accumulation of bacteria that cause dental caries, gingivitis, and periodontitis, which can eventually lead to the loss of teeth. ${ }^{2}$ Use of oral cleaning aids in oral hygiene practices has long been part of human civilization. Achieving ideal oral health should begin from childhood, and it is the collective responsibility of parents, teachers, and dentist to create a positive attitude regarding oral hygiene in children. ${ }^{3}$

This study assessed the knowledge, attitude, and oral hygiene practices of school children and the need for dental health education and intervention.

\section{Materials and Methods}

This descriptive cross-sectional study was conducted among male school children, aged 6-12 years, in two primary and two intermediate schools in Al-Zulfi, Riyadh Province, in Saudi Arabia. A total of 451 school children were included in this study using one-stage cluster sampling. Permission was obtained from the concerned school authorities and Ministry of Education before starting the study.
${ }^{1}$ Department of Dental Education, Majmaah University, Al Majmaah,
Kingdom of Saudi Arabia
${ }^{2-8}$ Department of Prosthodontics, College of Dentistry, Majmaah
University, Al Majmaah, Kingdom of Saudi Arabia
Corresponding Author: Subramania PK Kannan, Department of
Dental Education, Majmaah University, Al Majmaah, Kingdom of Saudi
Arabia, Phone: +9660538503869 , e-mail: drkkomr@gmail.com
How to cite this article: Kannan SPK, Alfahaid SF, Alharbi AS, et al. Oral
Hygiene Behavior of School Children in Saudi Arabia: A Descriptive
Cross-sectional Survey. Int J Clin Pediatr Dent 2020;13(1):66-71.
Source of support: Nil
Conflict of interest: None

Before the survey procedure, all participating children were subjected to an oral hygiene index-simplified assessment. ${ }^{4}$ To evaluate knowledge, attitude, and practices regarding oral health, a questionnaire comprising 33 questions, translated into Arabic, was used. ${ }^{5,6}$ The Arabic questionnaire was pretested for accuracy in a group of 30 school children on two occasions, with an interval of 10 days: responses to the questions were highly similar, with a kappa test coefficient for all questions of 0.92 .

With the prior permission from the Dean of the school and the children's parents, the dental health questionnaire was then explained to the students. Thereafter, the questionnaire was distributed among the children in the classrooms at the start of class, with the team of researchers present to clarify the questions and to collect all responses when the questionnaires had been completed.

The collected data were statistically analyzed using SPSS version 21 (SPSS Inc., Chicago, IL, USA). Data were compared using

(0) The Author(s). 2020 Open Access This article is distributed under the terms of the Creative Commons Attribution 4.0 International License (https://creativecommons. org/licenses/by-nc/4.0/), which permits unrestricted use, distribution, and non-commercial reproduction in any medium, provided you give appropriate credit to the original author(s) and the source, provide a link to the Creative Commons license, and indicate if changes were made. The Creative Commons Public Domain Dedication waiver (http://creativecommons.org/publicdomain/zero/1.0/) applies to the data made available in this article, unless otherwise stated. 
Table 1: Use of various tooth-cleaning aids used by children

\begin{tabular}{|c|c|c|c|c|c|c|c|c|}
\hline & & & \multicolumn{3}{|c|}{ Oral hygiene status } & \multirow[b]{2}{*}{ Total } & \multirow{2}{*}{$\begin{array}{l}\text { Chi-square } \\
\text { value }\end{array}$} & \multirow[b]{2}{*}{$p$ value } \\
\hline & & & Poor & Fair & Good & & & \\
\hline \multirow{10}{*}{$\begin{array}{l}\text { Material used for } \\
\text { brushing }\end{array}$} & Brush + toothpaste & Count & 49 & 137 & 142 & 328 & 23.575 & 0.003 \\
\hline & & $\%$ within oral hygiene status & 53.8 & 80.1 & 75.1 & 72.7 & & \\
\hline & Dental floss & Count & 3 & 4 & 3 & 10 & & \\
\hline & & $\%$ within oral hygiene status & 3.3 & 2.3 & 1.6 & 2.2 & & \\
\hline & Mouthwash & Count & 8 & 9 & 8 & 25 & & \\
\hline & & $\%$ within oral hygiene status & 8.8 & 5.3 & 4.2 & 5.5 & & \\
\hline & Toothpicks & Count & 8 & 5 & 9 & 22 & & \\
\hline & & $\%$ within oral hygiene status & 8.8 & 2.9 & 4.8 & 4.9 & & \\
\hline & Other methods & Count & 23 & 16 & 27 & 66 & & \\
\hline & & $\%$ within oral hygiene status & 25.3 & 9.4 & 14.3 & 14.6 & & \\
\hline \multirow[t]{2}{*}{ Total } & & Count & 91 & 171 & 189 & 451 & & \\
\hline & & $\%$ within oral hygiene status & 100.0 & 100.0 & 100.0 & 100.0 & & \\
\hline
\end{tabular}

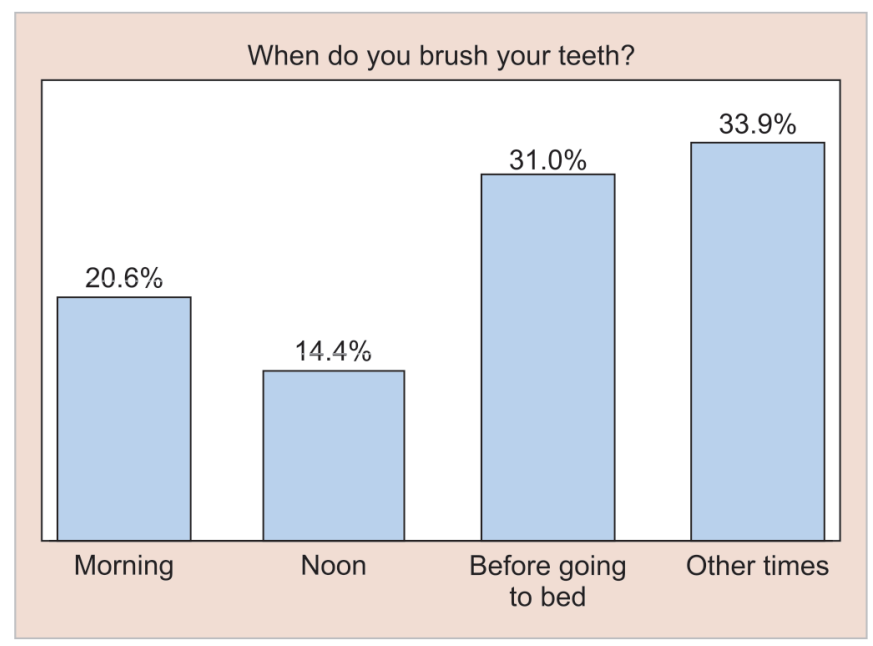

Fig. 1: Frequency of brushing

Chi-square tests, and if the calculated $p$ value is less than $<0.05$, then the difference is considered significant.

\section{Results}

We found that $72.7 \%(328 / 451)$ of the children used a toothbrush and toothpaste for cleaning their teeth, whereas 14.6\% (66/451) used other oral hygiene methods. Among the participants who had good oral hygiene, $75.1 \%(142 / 189)$ used a toothbrush and toothpaste, and $14.3 \%(27 / 189)$ used other hygiene methods. In contrast, among the participants who had poor oral hygiene, $53.8 \%$ (49/91) used a toothbrush and toothpaste, whereas $25.3 \%(23 / 91)$ used other oral hygiene methods. Only $2.2 \%$ (10/451) of the children overall used dental floss; only $1.6 \%$ (3/10) of these participants had good oral hygiene (Table 1).

Figure 1 shows that $31 \%(102 / 328)$ of children brushed their teeth before going to bed; $20.7 \%$ (68/328) of children overall brushed their teeth in the morning. Around $62.7 \%$ (283/451) children brushed their teeth for 1-2 minutes and accounted for $67.2 \%$ (127/189) of participants with good oral hygiene. In contrast, $26.6 \%$ (120/451) children brushed their teeth for less than 1 minute; among them $41.8 \%(38 / 120)$ of the participants were with poor oral hygiene. The difference was statistically significant $p=0.005$ (Table 2).

Only $27 \%$ (122/451) of the children correctly answered that plaque is a soft debris adherent to teeth (Fig. 2). Surprisingly, $55.9 \%(252 / 451)$ of the children did not know about the signs of periodontal diseases, such as bleeding gums and recession. In addition, $56.8 \%$ (256/451) of the children had no idea about the preventive and protective measures that should be followed to avoid gum bleeding, and only $11.3 \%$ (51/451) of them knew about healthy gingivae (Table 3).

During the children's last visit to a dentist, $22.8 \%$ (103/451) of them received restorations, $20.0 \%$ (90/451) of them had a checkup, $17.5 \%(79 / 451)$ had extractions, $10 \%(45 / 451)$ had scaling, $6.2 \%$ (28/451) had periodontal treatment, 5.1\% (23/451) underwent dental radiography, $4.7 \%(21 / 451)$ received topical fluoride application, $2.7 \%$ (12/451) underwent orthodontic treatment, and 2.2\% (10/451) received a crown and bridge (Table 4 ).

Fifty-eight percent (262/451) of the children visited a dental surgeon only when they had pain and only $11 \%$ (50/451) of the children regularly visited a dentist once in 6-12 months (Fig. 3). Around $29.5 \%$ (133/451) of children experienced severe dental pain when they first visited a dentist. A total of $32.2 \%$ (145/451) children were not afraid during their first dental visit and 22\% (99/451) of them were scared and reluctant to undergo treatment during their first visit (Table 5).

Sixty-one to eighty-two percent of students affirmed that carious teeth can affect their appearance, sweets affect teeth, brushing can prevent dental caries, fizzy drinks can affect teeth, and fluoride can be beneficial to teeth (Table 6). This study showed that only $41.9 \%$ (189/451) of children had a good oral hygiene status, whereas $20.2 \%$ (91/451) had a poor oral hygiene status (Fig. 4).

In terms of the role of parents, $48.3 \%$ (218/451) of the children's parents gave advice about tooth brushing to their children, but never watched them during brushing. Only 13.5\% (61/451) of the parents closely observed children during tooth brushing and $21.5 \%$ (97/451) of parents never cared about tooth brushing (Fig. 5).

\section{Discussion}

The habit of maintaining general hygiene and the formation of an appropriate attitude toward health mainly develop during childhood. 
Table 2: Duration of brushing

\begin{tabular}{|c|c|c|c|c|c|c|c|c|}
\hline & & & \multicolumn{3}{|c|}{ Oral hygiene status } & \multirow[b]{2}{*}{ Total } & \multirow{2}{*}{$\begin{array}{l}\text { Chi-square } \\
\text { value }\end{array}$} & \multirow[b]{2}{*}{$p$ value } \\
\hline & & & Poor & Fair & Good & & & \\
\hline \multirow{8}{*}{$\begin{array}{l}\text { Average duration taken } \\
\text { for single brushing }\end{array}$} & Less than 1 minute & Count & 38 & 44 & 38 & 120 & 18.575 & 0.005 \\
\hline & & $\%$ within oral hygiene status & 41.8 & 25.7 & 20.1 & 26.6 & & \\
\hline & 1 minute & Count & 24 & 68 & 66 & 158 & & \\
\hline & & $\%$ within oral hygiene status & 26.4 & 39.8 & 34.9 & 35.0 & & \\
\hline & 2 minutes & Count & 23 & 41 & 61 & 125 & & \\
\hline & & $\%$ within oral hygiene status & 25.3 & 24.0 & 32.3 & 27.7 & & \\
\hline & More than 2 minutes & Count & 6 & 18 & 24 & 48 & & \\
\hline & & $\%$ within oral hygiene status & 6.6 & 10.5 & 12.7 & 10.6 & & \\
\hline \multirow[t]{2}{*}{ Total } & & Count & 91 & 171 & 189 & 451 & & \\
\hline & & $\%$ within oral hygiene status & 100.0 & 100.0 & 100.0 & 100.0 & & \\
\hline
\end{tabular}

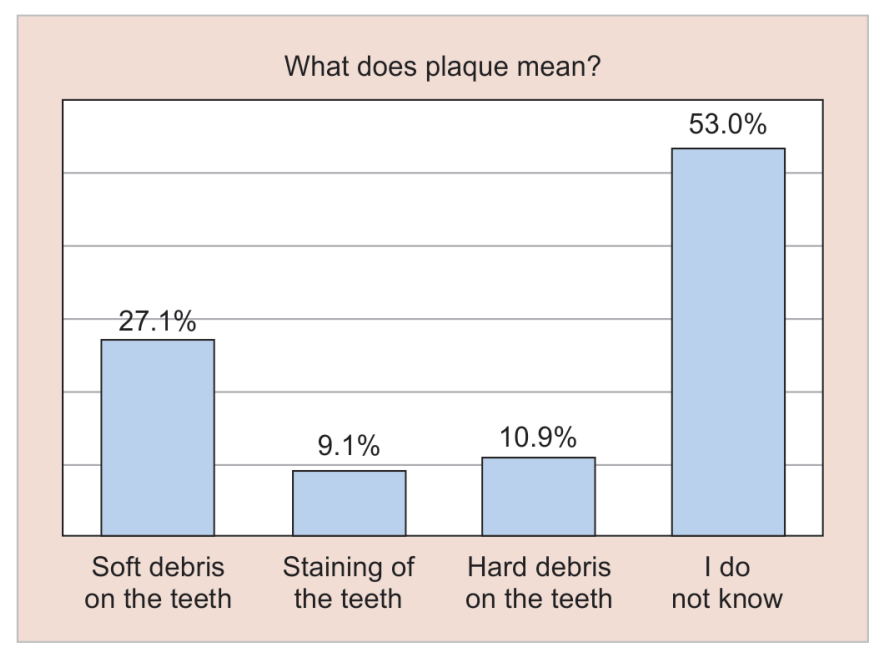

Fig. 2: Knowledge about dental plaque

Oral health is considered an integral component of general health. In this study, we assessed the knowledge and oral hygiene practices of male school children aged 6-12 years.

We found that $72.7 \%$ of children used a toothbrush and toothpaste, $2.2 \%$ used dental floss, $5.5 \%$ used mouth wash, and $4.9 \%$ used a toothpick. Similar findings were reported in a study from North Jordan, where $83 \%$ of the participating children used a toothbrush and toothpaste, $2 \%$ used dental floss, $6 \%$ used mouth wash, and $7 \%$ used a toothpick. ${ }^{5}$ In contrast, a study from Rijal Almaa (a rural area in southern Saudi Arabia) reported that only $58.4 \%$ of the participating children cleaned their teeth with a toothbrush and toothpaste, $32.1 \%$ used miswak, 7.2\% used a toothpick, and 2.3\% used dental floss. ${ }^{6}$ These comparable findings show that the target population have a positive attitude and practice of dental hygiene procedures.

In this study, $48.3 \%$ of children brushed their teeth at a convenient time rather than in the morning or before going to bed. Only $31 \%$ of children had a habit of brushing before going to bed, which is similar to the studies from Madinah and Rijal Almaa, in Saudi Arabia, in which $64.3 \%$ and $75 \%$ children brushed once daily, respectively. ${ }^{3,6}$ In contrast, in studies from Jordan, India, and Finland, $69 \%, 61 \%$, and $51 \%$ of participating children brushed their teeth twice daily, respectively. $5,7,8$

In this study, $62.7 \%$ of children generally brushed for around $1-2$ minutes. Only $10.6 \%$ of them brushed for more than 2 minutes;
Table 3: Children's knowledge about periodontal infection and gumprotective aids

\begin{tabular}{llrr}
\hline & & & \multicolumn{2}{c}{$\begin{array}{c}\text { Column } \\
\text { Valid n\% }\end{array}$} \\
\hline What does gum bleeding & Healthy gum & 51 & 11.3 \\
mean? & & \\
& Inflamed gum & 125 & 27.7 \\
& Gum recession & 23 & 5.1 \\
& I do not know & 252 & 55.9 \\
How do you protect your- & Using toothbrush, & 110 & 24.4 \\
self from gum bleeding? & paste, and dental floss & & \\
& Using soft food & 49 & 10.9 \\
& Using vitamin C & 36 & 8.0 \\
& I do not know & 256 & 56.8 \\
\hline
\end{tabular}

our results were comparable to similar study from Jordan and contrary to a study from Egypt, with values of $71 \%$ and $18.8 \%$, respectively. ${ }^{5,9}$ In this study, only $27.7 \%$ of children knew about gum bleeding and $24.4 \%$ knew that it could be prevented by tooth brushing and by use of floss, whereas $77.8 \%$ children knew that brushing could prevent decay. Regarding their diet, $82.7 \%$ of children agreed that sweets affect teeth and $71.8 \%$ agreed that fizzy drinks affect teeth adversely. These findings are in contrast to a study conducted in Africa, where only $52 \%$ were aware that brushing prevents gingival bleeding, $65 \%$ believed that brushing would prevent decay, and only $30 \%$ agreed that sweets affect teeth. ${ }^{10}$

In this study, $58 \%$ of children responded that they would visit the dentist only when they have a toothache, and only $11 \%$ had gone for regular dental checkups, whereas $18 \%$ had never visited a dentist. A study conducted in a rural area of Asser province in Saudi Arabia similarly reported that $54.6 \%$ of children's visits to dentists was for toothache. ${ }^{6}$ In a comparable study from Karachi, only $31.7 \%$ of the participants had visited a dentist; among them $26 \%$ children visited the dentist only when they had a dental problem, $3.5 \%$ children visited a dentist once a year, and $0.4 \%-0.7 \%$ visited a dentist every $3-6$ months, whereas $69.3 \%$ of children never visited a dentist. ${ }^{11}$ This finding could be attributed to the greater availability of information technology, and the availability of free medical and dental services from governmental medical institutions for the citizens of Saudi Arabia.

In this study, $61 \%$ of children had a good knowledge about fluoride and knew that it prevents dental caries. This is in contrast 
Table 4: Treatment of the child underwent during his/her last dental visit

\begin{tabular}{|c|c|c|c|}
\hline & & Count & Column valid $n \%$ \\
\hline \multirow{10}{*}{$\begin{array}{l}\text { The treatment(s) I sought during my last } \\
\text { visit to the dentist was (were): }\end{array}$} & Check my teeth & 90 & 20.0 \\
\hline & Take X-rays & 23 & 5.1 \\
\hline & Have scaling & 45 & 10.0 \\
\hline & Have fluoride on my teeth & 21 & 4.7 \\
\hline & Treat my gums & 28 & 6.2 \\
\hline & Have filling & 103 & 22.8 \\
\hline & Have crown/bridge & 10 & 2.2 \\
\hline & Have orthodontic treatment & 12 & 2.7 \\
\hline & Have tooth extraction & 79 & 17.5 \\
\hline & Others & 40 & 8.9 \\
\hline
\end{tabular}

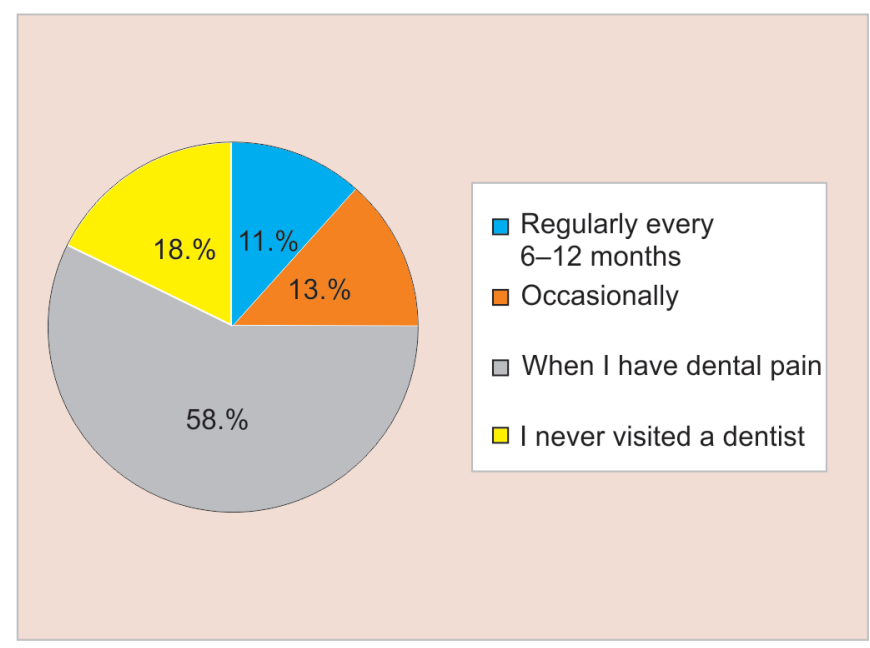

Fig. 3: Frequency of dental visit

to a similar study from Nepal, in which $82 \%$ of children aged $10-13$ years did not know about fluoride and its benefit to teeth. ${ }^{12} \mathrm{~A}$ study from Qatar showed that only $38.9 \%$ participant children were aware of fluoride and only $23.9 \%$ identified the preventive action of fluoride on dental decay. ${ }^{13}$ These differences could be attributed to socioeconomic factors and exposure to information on television and on the internet.

A study from Timis county showed that $11.2 \%$ children had never met a dentist. Of $87.8 \%$ of those who had visited a dentist,
$30.5 \%$ went for caries-related issues, $16.6 \%$ for extraction, and $8.1 \%$ for toothache. ${ }^{14}$ Among the children in this study, 75.4\% knew that caries can affect the appearance of a tooth. During their last visit to the dentist, $22.8 \%$ received restorations, $17.5 \%$ underwent tooth extraction, and $20 \%$ went for a checkup. A total of $65.2 \%$ of children in this study believed that regular visits to the dentist are necessary, whereas $17.7 \%$ never visited the dentist, indicating the attitude of children regarding oral hygiene. This finding indicates the present dental needs of Saudi school children, which is much higher than that in developed nations and signifies the role of creating awareness and preventive dental programs among school children. A study from Lithgow, Australia, reported that $53 \%$ of children had visited the dentist within the previous 6 months and $77 \%$ had done so within the previous year; the study also suggested that the age of the child and health insurance coverage was an influential factor in dentist visits. ${ }^{15}$ The attitude of children toward dentists or dental procedures was influenced by various factors, such as fear of the dental setup, lack of toothache, or lack of parental encouragement. $^{16}$

A study from Finland reported that children who had mothers with highly skilled occupations had good oral health-related knowledge, attitude, and oral hygiene behavior. ${ }^{17}$ A study from Qatar revealed that children received oral health information from parents $(69.1 \%)$, dentists $(8.6 \%)$, teachers $(5.1 \%)$, the media (3\%), house maids (2.1\%), and relatives (1.8\%). ${ }^{13}$ We agree with the statement made by Jalevik et al. in 1999 that lack of parents' regular visits to a dentist might be reflected in the children's attitude to dental matters. ${ }^{18}$ A similar study among school children in Al Hassa

Table 5: Child's first experience in the dental office

\begin{tabular}{|c|c|c|c|}
\hline & & Count & $\begin{array}{l}\text { Column } \\
\text { valid } n \%\end{array}$ \\
\hline \multirow[t]{7}{*}{ When I first visited the dentist: } & There was no dental pain & 94 & 20.8 \\
\hline & There was severe dental pain & 133 & 29.5 \\
\hline & There was little dental pain & 95 & 21.1 \\
\hline & I was not feeling comfortable & 50 & 11.1 \\
\hline & I felt nothing & 51 & 11.3 \\
\hline & There was not enough time for treatment & 10 & 2.2 \\
\hline & There was enough time for treatment & 18 & 4.0 \\
\hline \multirow[t]{4}{*}{ When I first visited the dentist: } & I was scared and reluctant & 99 & 22.0 \\
\hline & Slightly afraid & 118 & 26.2 \\
\hline & Very slightly afraid & 89 & 19.7 \\
\hline & I was never afraid & 145 & 32.2 \\
\hline
\end{tabular}


Table 6: Child's knowledge on etiology of dental caries

\begin{tabular}{|c|c|c|c|}
\hline & & Count & $\begin{array}{l}\text { Column } \\
\text { valid n\% }\end{array}$ \\
\hline \multirow{2}{*}{$\begin{array}{l}\text { Do you think you can decide the } \\
\text { treatment you need? }\end{array}$} & Yes & 215 & 47.7 \\
\hline & No & 236 & 52.3 \\
\hline \multirow{2}{*}{$\begin{array}{l}\text { Is it necessary for patients to decide } \\
\text { their dental treatment needs? }\end{array}$} & Yes & 314 & 69.6 \\
\hline & No & 137 & 30.4 \\
\hline \multirow{2}{*}{$\begin{array}{l}\text { Carious teeth can affect teeth } \\
\text { appearance }\end{array}$} & Yes & 340 & 75.4 \\
\hline & No & 111 & 24.6 \\
\hline \multirow[t]{2}{*}{ Sweets affect the teeth adversely } & Yes & 373 & 82.7 \\
\hline & No & 78 & 17.3 \\
\hline \multirow{2}{*}{$\begin{array}{l}\text { Brushing teeth prevents dental } \\
\text { decay }\end{array}$} & Yes & 351 & 77.8 \\
\hline & No & 100 & 22.2 \\
\hline \multirow{2}{*}{$\begin{array}{l}\text { Fizzy drinks affect the teeth ad- } \\
\text { versely }\end{array}$} & Yes & 324 & 71.8 \\
\hline & No & 127 & 28.2 \\
\hline \multirow[t]{2}{*}{ Using fluoride strengthens the teeth } & Yes & 277 & 61.4 \\
\hline & No & 174 & 38.6 \\
\hline
\end{tabular}

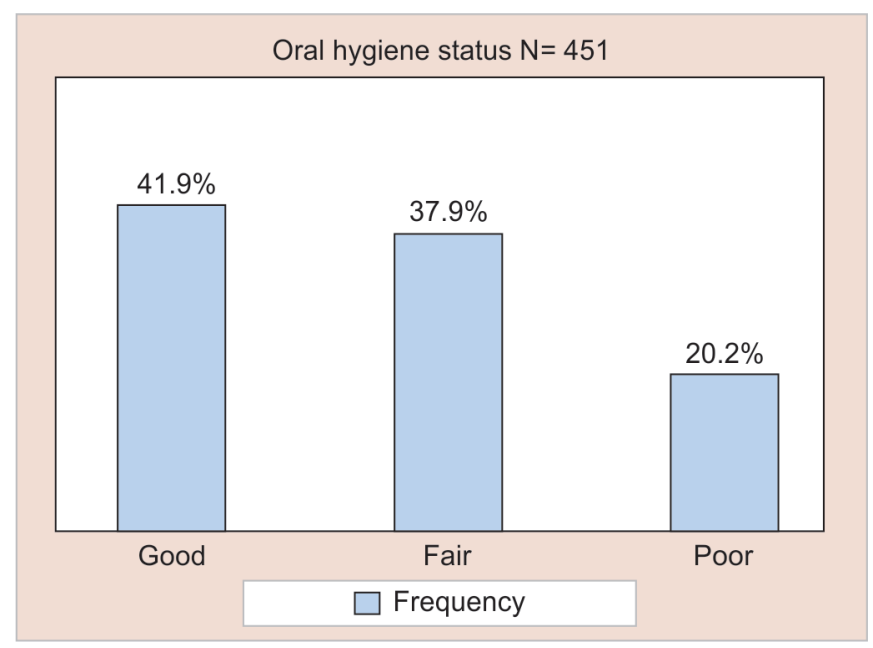

Fig. 4: Children's oral hygiene status

in 2008 revealed that the dental caries prevalence was higher among children with parents with a low education status, working mothers, and large families. ${ }^{19}$ Parental monitoring during tooth brushing is an influential factor for maintaining good oral hygiene; in this study, $48.3 \%$ of the parents did not supervise, but advised their children regarding brushing. A similar finding of $46 \%$ was reported by a study from Egypt. ${ }^{9}$ This finding reflects the necessity of dental preventive awareness programs and parental counseling.

In this study, only $41.9 \%$ of the children had a good oral hygiene status and $20.2 \%$ had a poor oral hygiene status; this indicates the necessity of educating children about oral hygiene. A similar study conducted among school children in India reported that $70.42 \%$ of children had a poor oral hygiene status and emphasized the importance of including education and motivation regarding maintaining oral health in the regular school curriculum. ${ }^{20}$ In a global school-based student survey conducted across 44 countries,

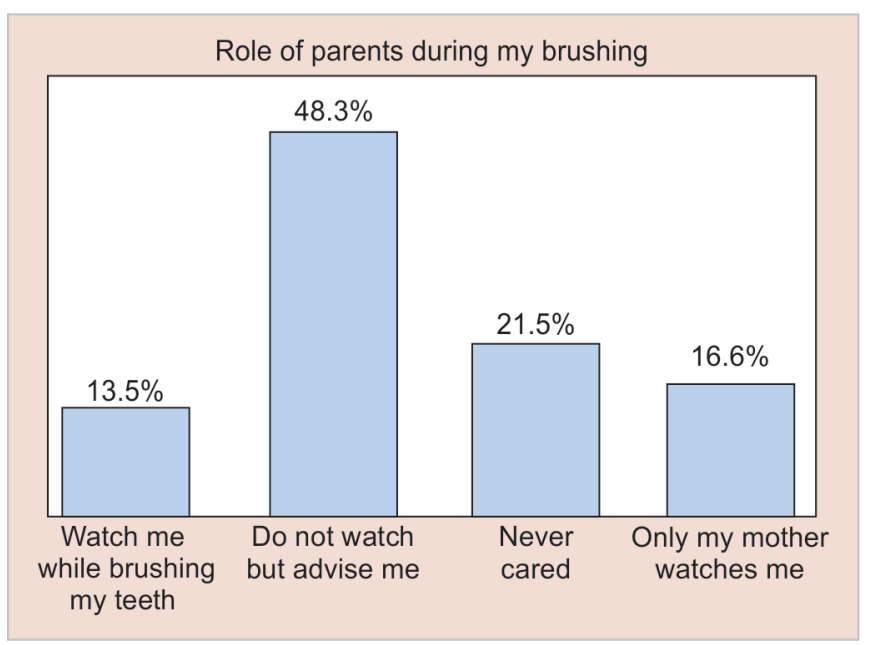

Fig. 5: Parental role in children's brushing habit

$80 \%$ of children brushed their teeth at least once daily, in 39 countries. Distressingly, more than $5 \%$ of children reported that they brushed less than once daily or never in 23 out of 44 countries. $^{21}$ A study conducted among intermediate school students in Riyadh showed that education had a positive effect on students' knowledge about oral hygiene, indicating the necessity of school dental health education programs. ${ }^{22}$

In summary, most of the children in this study knew that tooth brushing with a toothbrush and toothpaste helps to prevent dental caries, and they implement this behavior, but were unaware of the beneficial role of dental floss. Even with better awareness, only $41.9 \%$ had good oral hygiene. Moreover, the knowledge of these children about periodontal health was poor and around half of the students who participated in this study were not monitored by their parents during tooth brushing. These findings indicate the need for a comprehensive oral health education and motivational program including the children, teachers, and parents and also oral preventive care should be included in the school curriculum.

\section{Clinical Relevance}

Brushing with toothpaste is the most prevalent and most effective oral hygiene aid. Brushing twice a day, in the morning and before going to bed, for 1-2 minutes each time is beneficial. Oral health education should be included in the school curriculum, and a parental awareness program is needed to emphasize their role in the dental health of children.

The study was approved by Institutional ethical committee, and prior permission was obtained for this study in schools from Ministry of Education: L. no. 39374840.

\section{Consent for Participation}

Participants' parent consent was obtained.

\section{References}

1. Priya M, Devdas K, Amarlal D, et al. Oral health attitudes, knowledge and practice among school children in Chennai, India. J Educ Ethics Dent 2013;3:26-33. DOI: 10.4103/0974-7761.126940.

2. Arrow P, Raheb J, M Miller. Brief health promotion intervention among parents of young children to reduce early childhood dental decay. BMC Public Health 2013;13:245. DOI: 10.1186/1471-2458-13-245. 
3. Al-Samadani $\mathrm{KH}, \mathrm{Ahmad} \mathrm{MS}$, Bakeer HA, et al. Oral health knowledge and practice among 9-12-year-old schoolchildren in the region of Madinah, saudi Arabia and its impact on the prevalence of dental caries. Eur J Gen Dent 2017;6:54-58. DOI: 10.4103/2278-9626. 198615.

4. Greene JC, Vermillion JR. The simplified oral hygiene index. J Am Dent Assoc 1964;68:7-13. DOI: 10.14219/jada.archive.1964.0034.

5. Al-Omiri MK, Al-Wahadni AM, Saeed KN. Oral health attitudes, knowledge, and behaviour among school children in north Jordan. J Dental Ed 2006;70(2):179-187.

6. Al Subait AA, Alousaimi M, Geeverghese A, et al. Oral health knowledge, attitude and behavior among students of age 10-18 years old attending Jenadriyah festival Riyadh; a cross-sectional study. Saudi J Dental Res 2016;7:45-50. DOI: 10.1016/j.sjdr.2015.05.001.

7. Rafi AT, Syed MY, Zakirulla M, et al. Oral hygiene knowledge and practices among school children in a rural area of southern Saudi Arabia. Int J Contemp Dent 2012;3:57-62.

8. Pathania V, Sachdev V, Kirtaniya BC, et al. Oral health-related knowledge, attitude and practices amongst school children in Himachal Pradesh, India. Global J Med Res 2015;15:1-5.

9. Ahmed SM, Soliman AMA, Elmagrabi NM, et al. Oral health knowledge, attitude and practice among primary school children in rural areas of Assiut Governorate. Egypt J Com Med 2015;33:1-12. DOI: 10.21608/ejcm.2015.693.

10. Varenne B, Petersen PE, Ouattara S. Oral health behaviour of children and adults in urban and rural areas of Burkina Faso, Africa. Int Dental J 2006;56(2):61-70. DOI: 10.1111/j.1875-595X.2006.tb00075.x.

11. Bashir R, Rizvi K. Assessment of levels of oral hygiene awareness, knowledge, attitude and practice among the students of a government school in Karachi. Br J Med Med Res 2016;15:1-11. DOI: 10.9734/BJMMR/2016/24794.

12. Kumar A, Singh VP. Knowledge, attitude and practice of oral hygiene in children of eastern Nepal. J Dent Med Sci 2014;13:93-99. DOI: 10.9790/0853-13619399.
13. Al-Darwish MS. Oral health knowledge, behaviour and practices among school children in Qatar. Dent Res J 2016;13:342-353. DOI: 10.4103/1735-3327.187885.

14. Matichescu A, Matichescu ML, Ogodescu AS, et al. Oral hygiene behaviour, caries study of primary school children from Timis county. Rev Cercet Intervent Soc 2016;54:142-155.

15. John JR, Mannan H, Nargundkar S, et al. Predictors of dental visits among primary school children in the rural Australian community of Lithgow. BMC Health Serv Res 2017;17:264-274. DOI: 10.1186/s12913017-2232-1.

16. Taani DQ. Dental attendance and anxiety among public and private school children in Jordan. Int Dent J 2002;52(1):25-29. DOI: 10.1111/j.1875-595X.2002.tb00593.x.

17. Poutanen R, Lahti $\mathrm{S}$, Hausen $\mathrm{H}$. Oral health-related knowledge, attitudes, and beliefs among 11 to 12 -year-old Finnish schoo children with different oral health behaviours. Acta Odontol Scand 2005;63(1):10-16. DOI: 10.1080/00016350510019676.

18. Jalevik B, Sjostrom O, Noren JG. Evaluation of three years of dental care of adolescents in the public dental service in west Sweden. Sweden Dent J 1999;23(4):141-148.

19. Amin TT, Al-Abad BM. Oral hygiene practices, dental knowledge, dietary habits and their relation to caries among male primary school children in Al Hassa, Saudi Arabia. Int J Dent Hygiene 2008;6(4): 361-370. DOI: 10.1111/j.1601-5037.2008.00310.x.

20. Vishwanathaiah S. Knowledge, attitudes, and oral health practices of school children in Davangere. Int J Clin Pediatr Dent 2016;9(2):172-176. DOI: 10.5005/jp-journals-10005-1358.

21. Mckittrick TR, Jacobsen $\mathrm{KH}$. Oral hygiene practices among middle school students in 44 low-and middle-income countries. Int Dent J 2014;64(3):164-170. DOI: 10.1111/idj.12094.

22. Alotaibi AS, Jad A, Al-Sadhan AS. The impact of school based oral health education program on the level of oral health knowledge among public intermediate school girls at Riyadh. Dentistry 2016;7:430-441. 